\title{
Die verband tussen broeilingmassa en eiervolume in die Nylkrokodil (Crocodylus niloticus): Eiers se produktiwiteit varieer
}

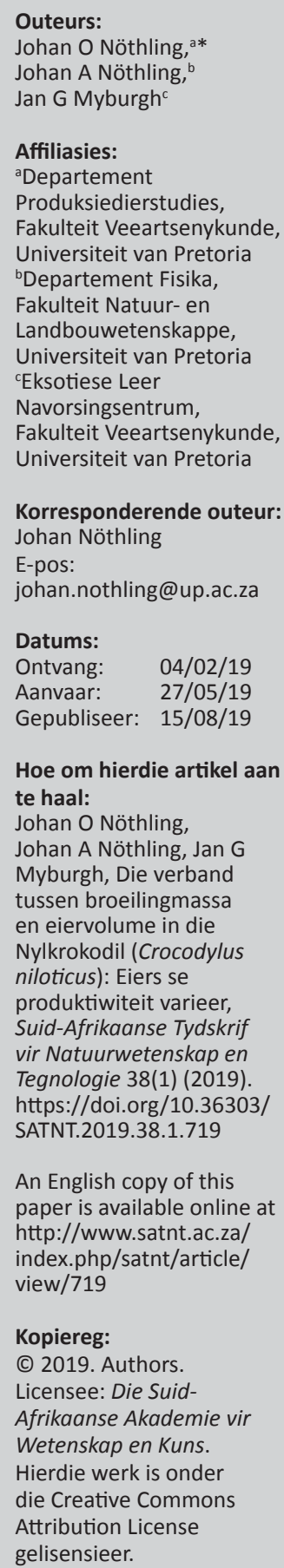

Die oorlewing en lewenskragtigheid van Nylkrokodil (Crocodylus niloticus) broeilinge is belangrik vir die sukses van kommersiële krokodilboerdery en die instandhouding van populasies in die natuur.

In hierdiestudie beskryf ons eers die verband tussen die massa van Nylkrokodilbroeilinge en die geskatte volume van die eier waaruit elkeen gebroei het. Daarna beskryf ons die variasie in die verhouding tussen die massa van individuele broeilinge en die volume van die eier waaruit elk gebroei het (die produktiwiteit van die eier) binne en tussen broeisels. Die volumes van 316 Nylkrokodileiers uit 51 broeisels is met 'n doelgemaakte algoritme geskat op grond van sleutelafmetings van die eiers wat op foto's van die uitgebroeide eierdoppe gemaak is. Die broeiling wat uit elke eier gebroei het is direk na uitbroei geweeg.

Nóg die duur van inkubering tot uitbroei $(\mathrm{P}=0.88)$ nóg die jaar waarin broeisels gelê is $(\mathrm{P}=0.35)$ nóg die aantal eiers in die broeisel $(\mathrm{P}=0.57)$ het broeilingmassa beïnvloed. Daar bestaan 'n sterk, lineêre positiewe verband tussen die uitbroeimassa van Nylkrokodilbroeilinge en die geskatte volume van die eiers waaruit hulle gebroei het $\mathrm{r}=0.88, \mathrm{P}<0.001$, $\mathrm{n}=316$ ). Sonder inagneming van geskatte eiervolume is $86.9 \%$ van die variasie in broeilingmassa die gevolg van variasie tussen broeisels en $13.1 \%$ die gevolg van variasie binne broeisels. Indien geskatte eiervolume in berekening gebring word is $59 \%$ van die variasie in broeilingmassa vir 'n bepaalde geskatte eiervolume die gevolg van variasie tussen broeisels en $41 \%$ die gevolg van variasie binne broeisels. Die produktiwiteit van eiers het van $0.57 \mathrm{~g} / \mathrm{ml}$ tot $0.81 \mathrm{~g} / \mathrm{ml}$ gevarieer, met $45.4 \%$ van die variasie wat tussen broeisels voorgekom het en $54.6 \%$ binne broeisels.

Verdere navorsing is nodig om die verband tussen broeilingmassa en die groei van broeilinge, sowel as die verband tussen eierproduktiwiteit en die groei van broeilinge te ondersoek.

Sleutelwoorde: Nylkrokodil, krokodil, eier, broeiling, volume

The relationship between hatchling mass and egg volume in the Nile crocodile (Crocodylus niloticus): The productivity of eggs varies: The survival and vitality of Nile crocodile (Crocodylus niloticus) hatchlings is important for the success of commercial crocodile farming and the maintenance of wild populations.

In this study we describe the relationship between the mass of Nile crocodile hatchlings and the estimated volume of the eggs from which they hatched and, following that, we describe the variation in the ratio between the mass of individual hatchlings and the egg volume from which each hatched (the productivity of the egg) within and among clutches. The volumes of 316 Nile crocodile eggs from 51 clutches were estimated by means of a purpose-made algorithm that uses key dimensions of eggs obtained from photos of the hatched shells. The hatchling from each egg was weighed immediately after hatching.

Neither the duration of incubation prior to hatching $(\mathrm{P}=0.88)$ nor the year in which clutches were laid $(P=0.35)$, nor the number of eggs per clutch $(P=0.57)$ affected hatchling mass. There exists a strong, linear, positive relationship between the mass of Nile crocodile hatchlings and the estimated volume of the eggs from which they hatched $(r=0.88, P$ $<0.001, \mathrm{n}=316$ ). Without considering estimated egg volume, $86.9 \%$ of the variation in hatchling mass occurs among clutches and $13.1 \%$ within clutches. Taking estimated egg volume into account, $59 \%$ of the variation in hatchling mass occurs among clutches and $41 \%$ within clutches. Egg productivity varied from $0.57 \mathrm{~g} / \mathrm{ml}$ to $0.81 \mathrm{~g} / \mathrm{ml}$, with $45.4 \%$ of the variation occurring among clutches and $54.6 \%$ within clutches.

Further research is required to investigate the relationship between hatchling mass and the growth of hatchlings, as well as between egg productivity and the growth of hatchlings.

Keywords: Nile crocodile, crocodile, egg, hatchling, volume 


\section{Inleiding}

Wilde Nylkrokodille (Crocodylus niloticus) word lank reeds as van groot ekologiese belang beskou in riviere en ander binnelandse waters in groot dele van Afrika (Pooley, 1973). Aan die begin van die twintigste eeu het Nylkrokodille van so ver noord as die Nyldelta (Brito et al., 2011) tot so ver suid as die oostelike deel van die Kaap (Feely, 2010) voorgekom. Vandag kom Nylkrokodille natuurlik van so ver noord as die suide van Egipte, Mauritanië in Wes Afrika en Tsjaad (Brito et al., 2011) voor en verder suid dwarsdeur Afrika (Fergusson, 2010) tot so ver as die St Luciameer in KwaZulu-Natal (Combrinck et al., 2013). Verskeie Nylkrokodilpopulasies krimp (Behangana et al., 2017; Botha et al., 2011; Calverley en Downs, 2014) of het onlangs erge mortaliteit ervaar (Ferreira en Pienaar, 2011).

Die teel van Nylkrokodille is van groot kommersiële belang in suidelike Afrika, vanweë die gesogtheid van hul leer (Fergusson, 2010; Tosun, 2013). Die oorlewing en groei van broeilinge het ' $n$ impak op die aantal en grootte van krokodille wat geslag word vir hul velle en daarom op leerproduksie en die ekonomie daarvan (Isberg et al., 2005). Op kommersiële krokodilplase in Suid-Afrika word broeilinge in gevangenskap geteel. Nylkrokodille paar in die water gedurende die tweede helfte van die winter en wyfies lê hul eiers in die lente in gate wat hulle in sand langs die water grawe (Kofron, 1990). Daar is gemiddeld ongeveer 40 eiers per broeisel maar broeiselgrootte varieer baie (Khoza, 2012). Op plase word die eiers die oggend nadat hulle gelê is uitgegrawe en kunsmatig geïnkubeer teen 'n konstante temperatuur en lugvog.

Garnet en Murray (1986) het bevind dat die gemiddelde broeilingmassa van elk van agt broeisels van die soutwaterkrokodil (Crocodylus porosus) gevarieer het van 40 gram tot 80 gram, terwyl die standaardafwykings wat hulle rapporteer toon dat die massa van broeilinge van dieselfde broeisel dikwels met ongeveer 16 gram en tot soveel as ongeveer 20 gram gevarieer het.

Die gemiddelde broeilingmassa van Amerikaanse alligator (Alligator mississippiensis) broeisels toon 'n sterk positiewe lineêre verband met hul gemiddelde eiermassas (Deitz en Hines, 1980). Net so toon Garnet en Murray (1986) en Stoker et al. (2013) se data onderskeidelik 'n sterk positiewe verwantskap tussen die gemiddelde broeilingmassas van die broeisels met hul gemiddelde eiermassas in Crocodylus porosus en die breësnoetkaaiman (Caiman latirostris). Webb et al. (1983a) het bevind dat die massa van die Australiese varswaterkrokodil (Crocodylus johnstoni) se broeilinge na verwagting met $0.62 \mathrm{~g}$ toeneem vir elke een gram toename in eiermassa en dat eiermassa $89 \%$ van die variasie in broeilingmassa verklaar. Webb et al. (1983b) bevind dat die massa van Crocodylus porosus broeilinge na verwagting met $0.64 \mathrm{~g}$ toeneem vir elke een gram toename in eiermassa en dat eiermassa $79 \%$ van die variasie in broeilingmassa verklaar.
Deitz en Hines (1980) en Garnett en Murray (1986) het onderskeidelik bevind dat die gemiddelde eiermassa van Alligator mississippiensis en Crocodylus porosus broeisels baie meer gevarieer het as die massa van individuele eiers binne broeisels. Stoker et al. (2013) het egter gerapporteer dat die variasie in eiermassa binne Caiman latirostris broeisels groter was as die variasie tussen die gemiddelde eiermassas van broeisels.

Broeisel het ' $n$ beduidende effek op die groei van Crocodylus porosus broeilinge (Brien et al., 2014; Garnett en Murray, 1986) en die voorkoms van broeilinge wat uitermate swak groei (Brien et al., 2014).

Garnett en Murray (1986) se resultate toon dat die massa van individuele Crocodylus porosus broeilinge in die meerderheid van die agt broeisels in hul studie meer gevarieer het as die massa van individuele eiers in dieselfde broeisels. Dit mag daarop dui dat die massa van broeilinge wat eiers van 'n bepaalde massa oplewer mag varieer.

Groter Nylkrokodilwyfies lê groter eiers as kleiner wyfies (Huchzermeyer, 2003; Swanepoel et al., 2000). Alhoewel hul steekproef te klein was om 'n betekenisvolle effek te bevestig, dui Deitz en Hines (1980) se data daarop dat groter Amerikaanse alligatorwyfies groter eiers lê as kleiner wyfies.

Verskeie van bogenoemde studies het broeilingmassa in verband gebring met eiermassa maar geen het broeilingmassa met eiervolume in verband gebring nie. Die massa van krokodileiers is makliker om te bepaal as hul volume, mits die eiers beskikbaar is om te weeg. Sulke toestande geld op kommersiële plase waar eiers roetinegewys van die nesse verwyder word en in studies waar nesse in die natuur oopgemaak word voordat die eiers uitbroei (Swanepoel et al., 2000). Alhoewel meer omslagtig as om eiers te weeg, kan die volume van intakte eiers sowel as eiers wat reeds uitgebroei het bepaal word (Nöthling et al., 2019). Indien die verhouding tussen eiermassa en eiervolume - die soortlike gewig van eiers - konstant sou wees, sal die verhouding tussen broeilingmassa en eiervolume geen inligting verskaf wat nie ook deur die verhouding tussen broeilingmassa en eiermassa verskaf sou word nie. In daardie geval kan die een met die ander vervang word. Die soortlike gewig van Nylkrokodileiers, sowel as die variasie daarvan, is egter onbekend. Die vermoë om die volume van Nylkrokodileiers op grond van die uitgebroeide eierdoppe te skat stel mens in staat om eiergrootte met broeilingmassa in verband te bring op plase waar eiergrootte nié voor uitbroeiing bepaal is nie. Verder sal die skatting van die volumes van eiers op grond van die uitgebroeide doppe in nesse in die natuur - nadat die broeilinge die veiligheid van die water bereik het - mens in staat stel om die grootte van die wyfie wat die eiers gelê het, sowel as die grootte van die broeilinge wat die nes opgelewer het te skat. Nöthling et al. (2019) het getoon dat die volume van 'n Nylkrokodileier met 'n 95\% sekerheid tot binne $4.57 \mathrm{ml}$ van sy werklike volume geskat kan word uit metings op 'n foto van die uitgebroeide eierdop. 
Daar is na ons wete nog geen studie gedoen om die verband tussen die grootte van individuele eiers en die massa van die broeilinge wat uit elkeen gebroei het, asook die variasie van hierdie verband binne en tussen broeisels te beskryf nie.

Die doel van hierdie studie was om die verband tussen die massa van Nylkrokodilbroeilinge en die geskatte volume van die eier waaruit elkeen gebroei het, asook die variasie in die verhouding tussen die massa van individuele broeilinge en die volume van eier waaruit elk gebroei het (die produktiwiteit van die eier) binne en tussen broeisels te beskryf.

\section{Materiale en metodes}

Die navorsing is goedgekeur deur die Animal Ethics Committee van die Universiteit van Pretoria (projek V07114, V078-14).

\section{Versameling van eierdoppe en broeilinge}

Nylkrokodilbroeilinge met die eierdoppe waaruit hulle gebroei het is gedurende twee broeiseisoene op 'n enkele kommersiële plaas in die Noordwes-provinsie van SuidAfrika versamel. Drie honderd een en tagtig broeilinge met hul eierdoppe is van 52 broeisels versamel (2-18 per broeisel) terwyl hulle besig was om uit te broei of direk nadat hulle uitgebroei het, terwyl hulle nog met hul naelstringe aan hul doppe verbind was.

\section{Weeg van broeilinge}

Sodra elke broeiling se naelstring gebreek het is dit tot die naaste 0.1 gram geweeg.

\section{Foto's van die eierdoppe}

Die grootste onbeskadigde deel van die dop is binne 5 minute nadat die broeiling uitgebroei en sy naelstring gebreek het gefotografeer soos beskryf deur Nöthling et al. (2019) met dié beperking dat die pool waardeur die broeiling die dop verlaat het na bo afgeneem is.

\section{Skat van die volume van uitgebroeide eiers}

Die foto van elke eierdop is voorberei, waarna die drempelwaarde vir die identifisering van eierpiksels en die omstipte eierrand bepaal is soos deur Nöthling et al. (2019) beskryf. Daarna is die posisie van die poolas bepaal soos Nöthling et al. (2019) vir gemaskeerde eierbeelde beskryf het, waarna die posisie van die buiklyn (grootste dwarsdeursnit, loodreg op die poolas) bepaal is. Daarna is verskeie deursneë loodreg op die poolas gemeet soos deur Nöthling et al. (2019) beskryf vir gemaskeerde beelde van heel eiers.

Vir elke eierdopbeeld waar deursneë loodreg op die geskatte poolas gemeet kon word tot 'n hoogte van minstens 1.3 maal die afstand van die onderste pool tot die buik (d.w.s. eierdopbeelde met ' $n$ bestek van minstens 1.3) is die polariteit bepaal soos beskryf deur Nöthling et al. (2019). Die polariteit van 'n eier is bepaal as die som van die lengtes van die deursnitte op hoogtes 1.05, 1.1, 1.15, 1.2, 1.25 en 1.3 maal die afstand van die onderste pool tot die buik minus dié van die deursnitte op hoogtes $0.7,0.75,0.8$, $0.85,0.9$ en 0.95 maal die afstand van die onderste pool tot die buik. 'n Eier se polariteit was minus een indien hierdie verskil minus een millimeter of minder was, nul indien dit tussen minus een en een millimeter was en een indien dit een millimeter of meer was. Afhangend van die bestek en polariteit van elke eier is die volume daarvan met die toepaslike model (Beperk-Akaike, Vol-Akaike of Vol, soos gedefinieer in Nöthling et al. (2019)) geskat. Voortaan word hierdie volumes die geskatte volumes van uitgebroeide eiers genoem.

\section{Data-ontleding}

\section{Data opsomming}

Data met ' $n$ normale verspreiding is as die gemiddeld en standaardafwyking opgesom en data met 'n skewe verspreiding as persentiele. Data is aanvanklik vasgelê en deels voorberei met Excel (Microsoft Office 2013). STATA weergawe 14 (StataCorp, 4905 Lakeway Drive, College Station, Texas 77845 USA) is vir die meeste van die datavoorbereiding en die data-analise gebruik. Afrikaanse statistiekterme is verkry uit Steyn et al. (1998) en Steyn et al. (2009).

Die verband tussen broeilingmassa en geskatte eiervolume met inagneming van die effek van broeisel en ander koveranderlikes

Broeiduur is as koveranderlike by die model ingesluit om die effek daarvan op broeilingmassa te bepaal. Data is gedurende twee broeiseisoene versamel. Die effek van die jaar waarin elke broeisel gelê is mag dus met dié van broeilingmassa en eiervolume verstrengel wees en jaar is derhalwe as strengelingsfaktor by die model ingesluit. Die effek van die aantal eiers in 'n broeisel (broeiselgrootte) op broeilingmassa kon óók met dié van geskatte eiervolume verstrengel wees en broeiselgrootte is daarom óók as strengelingsveranderlike by die model ingesluit. Omdat die effekte van die moer op broeilingmassa ook met dié van eiervolume op broeilingmassa verstrengel kon wees is hulle gekontroleer deur broeisel as stogastiese groepsveranderlike by die model in te sluit.

Meervoudige gemengde-effek regressie is gebruik om die effek van die geskatte volume van uitgebroeide eiers op broeilingmassa te beraam. Die volledige model vir die beraming van broeilingmassa word in vergelyking 1 gegee:

Vergelyking 1: $\quad y_{i j}=\beta_{0}+\beta_{1} x_{1 i j}+\beta_{2} x_{2 j}+\beta_{3} x_{3 j}+\beta_{4} x_{4 j}+u_{j}+\varepsilon_{i j}$.

$y_{i j}$ Is die broeilingmassa van die $i$-de eier uit die $j$-de broeisel. $\beta_{0}+\beta_{1} x_{1 i j}+\beta_{2} x_{2 i j}+\beta_{3} x_{3 i j}+\beta_{4} x_{4 i j}$ definieer die lineêre regressielyn van die vaste komponent van die model met $\beta_{0}$ die $y$-afsnit daarvan. $\beta_{1} x_{1 i j}$ Beraam die effek van die geskatte volume van die $\mathrm{i}$-de uitgebroeide eier uit die $\mathrm{j}$-de broeisel op die massa van die $i$-de broeiling uit die $j$-de broeisel, $\beta_{2} x_{2 j}$ 
die effek van jaar daarop, $\beta_{3} x_{3 j}$ die effek van broeiselgrootte daarop en $\beta_{4} x_{4 j}$ die effek van die broeiduur van die $j$-de broeisel daarop. $u_{j}$ Beraam die gekombineerde effek van ongemete eienskappe wat geassosieer word met die j-de broeisel op die massa van die i-de broeiling uit die j-de broeisel. $\varepsilon_{\mathrm{ij}}$ Beraam die gekombineerde effek van ongemete eienskappe wat geassosieer word met die i-de broeiling uit die j-de broeisel op die massa daarvan. Die finale model word in vergelyking 2 gegee. Die finale model is dieselfde as dié in vergelyking 1 behalwe dat alle koveranderlikes wat geen betekenisvolle effek op broelingmassa gehad het nie, uitgelaat is.

Die gepasde broeilingmassa het die vaste effek van die finale model, naamlik die lineêre regressie van die werklike broeilingmassa op die geskatte volume van die uitgebroeide eier, sowel as die bydrae van die beraamde stogastiese effek van broeisel in die finale model ingesluit. Die verskil tussen die werklike broeilingmassa en gepasde broeilingmassa is as 'n persentasie van die gepasde broeilingmassa uitgedruk (persentasie fout in die gepasde broeilingmassa).

\section{Vergelyking van die persentasiefoute in die gepasde volume van onuitgebroeide, heel eiers met die persen- tasiefoute in die gepasde broeilingmassa}

Nöthling et al. (2019) het die werklike volumes van 138 heel Nylkrokodileiers, wat nie uitgebroei het nie, deur integrasie van metings wat hulle d.m.v. 'n rekenaarprogram op 'n digitale fotobeeld van elke eier gedoen het, bereken. $\mathrm{Na}$ hierdie eiers word voortaan verwys as eiers met bekende volume. Hulle het daarna die fotobeeld van elk van die 138 eiers tot verskillende mates gemaskeer deur $15-30 \%$ van die boonste deel van die eierbeeld vir meting te verberg, wat die situasie nageboots het indien fotobeelde van uitgebroeide eierdoppe gemeet sou word. Nöthling et al. (2019) het elkeen van 524 gemaskeerde fotobeelde (1-4 van elk van die 138 eiers), gebruik om die volume van die eier op elke fotobeeld te skat.

Vir 487 van hierdie gemaskeerde eierbeelde het die geskatte volume binne dieselfde grense geval as dié van die 316 uitgebroeide eiers in die huidige studie waarvan die broeilingmassas bekend is. Hierdie 487 geskatte volumes behels 1-4 skattings van die volume van 127 eiers met bekende volume uit 35 broeisels, met $1-5$ eiers per broeisel. 'n Drievlak gemengde-effek regressie, met die werklike volume van hierdie 127 eiers as uitkomsveranderlike, hul 487 geskatte volumes as vaste effek, eieridentiteit as tweedevlak stogastiese effek en broeisel as derdevlak stogastiese effek is gebruik om die gepasde eiervolume vir elke geskatte volume te beraam (Rabe-Hesketh en Skrondal, 2012). Hierdie 487 gepasde volumes van die eiers met bekende volume het die vaste effek, naamlik die lineêre regressie van hul werklike volumes op hul geskatte volumes, sowel as die bydrae van die beraamde stogastiese effekte van eier en broeisel ingesluit. Die verskil tussen die werklike volume van elke eier en sy gepasde volume is as 'n persentasie van die gepasde volume uitgedruk (persentasie fout in gepasde volume van eiers met bekende volume).

Nöthling et al. (2019) het aangetoon dat die presisie waarmee ' $n$ eier se volume geskat word toeneem na mate die bestek van die dop toeneem. Wilcoxon se rangsomtoets is gebruik om die bestek van die 316 uitgebroeide eierdoppe met dié van die 487 gemaskeerde eierbeelde te vergelyk.

Indien die fout in die gepasde broeilingmassa uitsluitlik as gevolg van foutiewe skatting van die volume van uitgebroeide eiers was sou die variansie van die persentasie fout in gepasde broeilingmassa en die variansie van die persentasie fout in gepasde volume van eiers met bekende volumes gelyk wees. Die variansies van die twee stelle persentasiefoute is m.b.v. Levene se toets vergelyk om te bepaal of die variansie van die persentasie fout in gepasde broeilingmassa groter is as die variansie van die persentasie fout in gepasde volume van eiers met bekende volume.

\section{Bepaling van die variasie van die geskatte volume van uitgebroeide eiers en broeilingmassa binne- en tussen broeisels}

Die variasie van die geskatte volume van uitgebroeide eiers binne broeisels relatief tot die variasie daarvan tussen broeisels is bepaal deur die intraklaskorrelasiekoëffisiënt van geskatte eiervolume te bereken in 'n model wat geskatte eiervolume as uitkomsveranderlike ingesluit het en broeisel as stogastiese groepveranderlike, sonder enige koveranderlikes (Rabe-Hesketh en Skrondal, 2012). Net so is die variasie van broeilingmassa binne- en tussen broeisels bepaal deur die intraklaskorrelasiekoëffisiënt van broeilingmassa in 'n model met broeilingmassa as uitkomsveranderlike en broeisel as stogastiese groepveranderlike, sonder enige koveranderlikes te bereken. Beide hierdie intraklaskorrelasiekoëffisiënte is bereken op die 270 geskatte eiervolumes en die 270 broeilingmassas uit die 34 broeisels wat elk minstens vyf data vir elke veranderlike gehad het.

\section{Die bepaling van eierproduktiwiteit en die variasie daar- van binne- en tussen broeisels}

Die geskatte gram broeiling per milliliter eier (die produktiwiteit van 'n eier) is bereken deur die massa van 'n broeiling deur die geskatte volume van die eier waaruit dit gebroei het te deel. Eierproduktiwiteit is opgesom en grafies gedemonstreer. Die intraklaskorrelasiekoëffisiënt van eierproduktiwiteit is in ' $n$ model met eierproduktiwiteit as uitkomsveranderlike en broeisel as stogastiese groepveranderlike, sonder enige koveranderlikes, bepaal.

\section{Resultate}

Opsomming van uitgebroeide doppe en geskatte eiervolumes, en broeilingmassa

Van die 381 broeilinge waarvoor dit bekend was uit watter eier elk gebroei het en wat geweeg is, was 330 se eierdoppe heel genoeg om betroubare metings tot bokant die buik op te lewer, sodat die buiklyn se posisie en snypunt met die 
poolas bepaal kon word. Hiervan was 316 uit 51 broeisels heel genoeg om betroubare metings tot ' $n$ hoogte van minstens 1.3 maal die afstand van die onderste pool tot die buik op te lewer en waarvan die eiervolume derhalwe geskat kon word (Nöthling et al., 2019). Een tot 14 van hierdie 316 waarnemings kom uit dieselfde broeisel (gemiddeld 6.2 , standaard afwyking = 3.35). Die 316 eierdop-beelde se polariteit was $-1(n=83), 0(n=121)$ en $1(n=112)$.

Die verspreiding van die geskatte volume van die 316 uitgebroeide eiers was negatief skeef (minimum 57.1 ml, onderste kwartiel $92.6 \mathrm{ml}$, mediaan $99.9 \mathrm{ml}$, boonste kwartiel $106.1 \mathrm{ml}$, maksimum $121.7 \mathrm{ml}$ ). Die verspreiding van die 316 broeilingmassas was ook negatief skeef (minimum $41.1 \mathrm{~g}$, onderste kwartiel $64.0 \mathrm{~g}$, mediaan $69.9 \mathrm{~g}$, boonste kwartiel $76.0 \mathrm{~g}$, maksimum $86.2 \mathrm{~g}$ ).

\section{Die verband tussen broeilingmassa en die geskatte volume van die eier waaruit elk gebroei het}

Figuur 1 toon dat daar in die meeste broeisels 'n positiewe verband tussen broeilingmassa en geskatte eiervolume was. Figuur 1 toon ook dat daardie broeisels met betreklik lae geskatte eiervolumes ook betreklik lae broeilingmassas gehad het, terwyl die broeisels met betreklik hoë geskatte eiervolumes ook betreklik hoë broeilingmassas gehad het. Figuur 2, wat die data van al 51 broeisels saam vertoon, toon 'n sterk positiewe lineêre verband tussen broeilingmassa en geskatte eiervolume (Spearman se rangkorrelasiekoëffisiënt 0.88, $\mathrm{n}=316, \mathrm{P}<0.001)$. Figuur 2 toon ook dat, indien die broeisels waaruit eiers kom nie oorweeg word nie, 'n beduidende spreiding van broeilingmassas vir ' $n$ bepaalde geskatte eiervolume voorgekom het.

Broeiduur het broeilingmassa nie beduidend beïnvloed nie $(P=0.88)$ en is daarom uit die finale model vir die beraming van broeilingmassa gelaat. Tabel 1 toon dat die geskatte eiervolume 'n hoogs betekenisvolle effek op broeilingmassa het. Tabel 1 toon ook dat nóg die jaar waarin broeisels gelê is nóg broeiselgrootte ' $n$ beduidende effek op broeilingmassa gehad het en dat die koëffisiënte van die afsnit en geskatte eiervolume weinig verander wanneer jaar en broeiselgrootte uit die model weggelaat is. Jaar en broeiselgrootte is derhalwe uit die finale model gelaat wat in vergelyking 2 beskryf word:

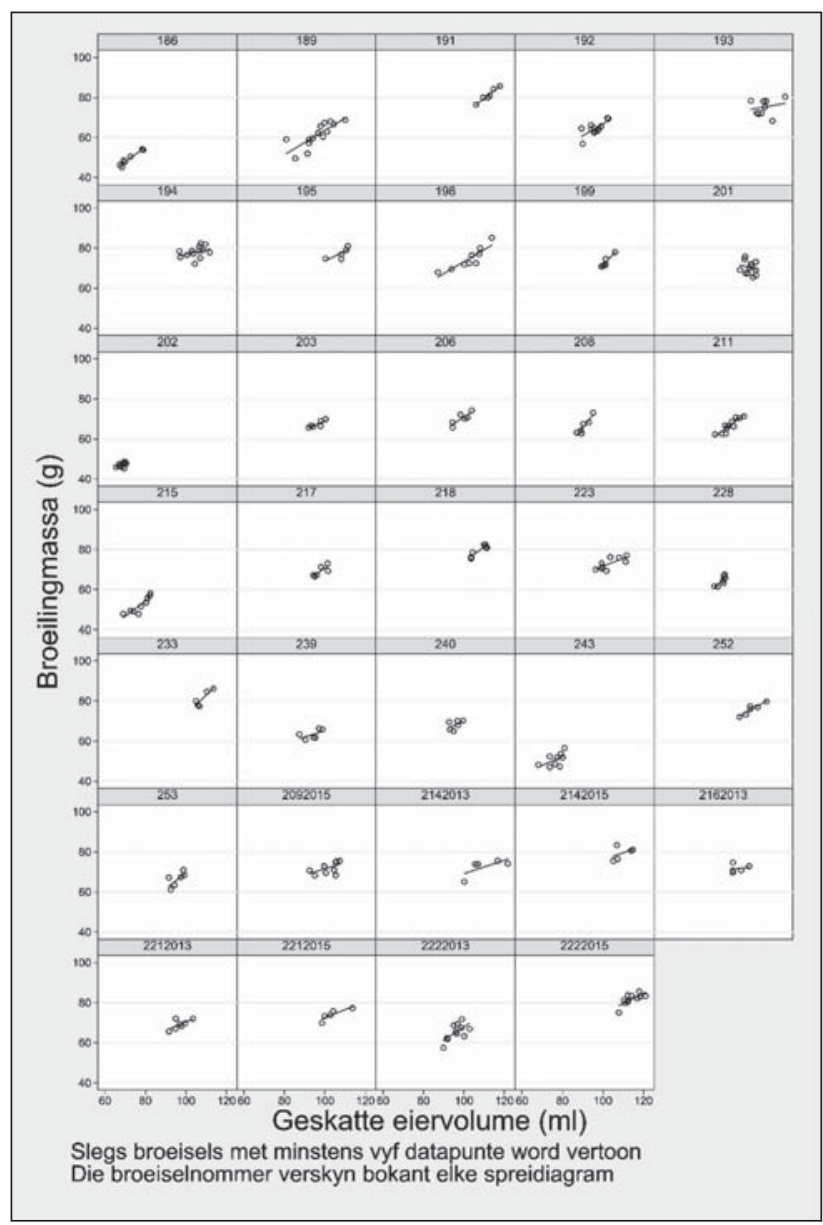

FIGUUR 1: Die verband tussen die uitbroeimassa van broeilinge en geskatte eiervolume in 34 Nylkrokodilbroeisels

Vergelyking 2: $\mathrm{y}_{\mathrm{ij}}=\beta_{0}+\beta_{1} \mathrm{x}_{1 \mathrm{ij}}+\mathrm{u}_{\mathrm{j}}+\varepsilon_{\mathrm{ij}}$ met die betekenis van elke simbool soos vir verglyking 1 gedefinieer.

Die finale model het $84.6 \%$ van die variasie in broeilingmassa beskryf (Wald $\chi^{2}=566$, met een graad van vryheid).

Die regressievergelyking om broeilingmassa uit geskatte eiervolume te beraam is soos volg:

Broeilingmassa $=8.82+0.61 \times$ geskatte eiervolume $($ die standaardfout van die koëffisiënt was 0.026 en die $95 \%$ vertrouensinterval $0.56-0.66, z=23.8, \mathrm{P}<0.001$ ).

Met die finale model, wat die effek van geskatte eiervolume in berekening bring, het $59.2 \%$ van die variasie in broei-

TABEL 1: Die koëffisiënte van die vaste komponent van die model vir die beraming van broeilingmassa.

\begin{tabular}{|c|c|c|c|c|}
\hline \multirow[b]{2}{*}{ Veranderlike } & \multicolumn{4}{|c|}{ Regressiekoëffisiënt } \\
\hline & Identiteit $^{\mathrm{a}}$ & Verwagte waarde & $95 \% v^{b}$ & $\mathbf{P}$ \\
\hline \multirow[t]{2}{*}{$\overline{\text { Afsnit }}$} & $\beta_{0}$ & 8.83 & $2.20,15.46$ & 0.01 \\
\hline & & $(8.82 c)$ & $(3.79,13.85)$ & $(0.001)$ \\
\hline \multirow[t]{2}{*}{ Geskatte eiervolume } & $\beta_{1}$ & 0.60 & $0.55,0.66$ & $<0.001$ \\
\hline & & $(0.61)$ & $(0.56,0.66)$ & $(<0.001)$ \\
\hline Jaar & $\beta_{2}$ & -0.90 & $-2.79,0.99$ & 0.35 \\
\hline Broeiselgrootte & $\beta_{3}$ & 0.04 & $-0.09,0.17$ & 0.57 \\
\hline
\end{tabular}

a Die identiteit van die koëffisiënte soos dit in vergelykings 1 en 2 verskyn

${ }^{b}$ Die grense van die $95 \%$ vertrouensinterval

c Alle waardes tussen hakies geld vir die finale model, wat jaar en broeiselgrootte uitsluit, omdat hulle geen betekenisvolle effek op broeilingmassa gehad het nie. 
lingmassa tussen broeisels voorgekom en $40.8 \%$ binne broeisels. Die effek van broeisel op broeilingmassa was hoogs betekenisvol in die finale model $\left(\chi^{2}=128,1\right.$ graad van vryheid, $\mathrm{P}<0.001,316$ broeilingmassas in 51 broeisels).

\section{Die persentasiefoute in gepasde volume van onuit- gebroeide, heel eiers en die persentasiefoute in gepasde broeilingmassa}

Die 316 uitgebroeide eierdopbeelde se bestek het gevarieer van 1.3 tot 1.8 (mediaan 1.6, onderste kwartiel 1.5, boonste kwartiel 1.7), wat hoër was as die bestek van die 487 gemaskeerde beelde van onuitgebroeide eiers (mediaan 1.5, onderste kwartiel 1.4, boonste kwartiel 1.6), $z=8.84, \mathrm{P}$ $<0.001$.

Figuur 3a toon dat 50\% van die persentasiefoute waarmee die volume van heel eiers op hul geskatte volumes gepas is binne die band van $-0.37 \%$ tot $0.39 \%$ van die gepasde eiervolume en $95 \%$ binne die band van $-1.44 \%$ tot $1.47 \%$ daarvan val. Figuur $3 b$ toon dat $50 \%$ van die persentasiefoute met die passing van die massas van broeilinge op die geskatte volumes van die eiers waaruit hulle gebroei het binne die band van $-1.83 \%$ tot $2.07 \%$ van die gepasde broeilingmassa en $95 \%$ binne die band van $-7.99 \%$ tot $6.80 \%$ daarvan val. Die interval tussen die 2.5 de en 97.5 de persentiel in die spreiding van die persentasiefoute met die passing van broeilinge se massas op die geskatte volumes van die eiers waaruit hulle gebroei het, is 5.1 maal wyer is as die ooreenstemmende interval in die spreiding van die persentasiefoute met die passing van die volume van heel onuitgebroeide eiers op húl geskatte volumes. Die variansie van die 316 persentasiefoute waarmee die massa van broeilinge op die volume van die eiers waaruit hulle gebroei het gepas is, is betekenisvol hoër as die variansie van die 487 persentasiefoute waarmee die volume van heel, onuitgebroeide eiers op húl geskatte volumes gepas is (Levene se toetsgrootheid $\mathrm{W}_{0}=392.5$ (F-verdeel met 1, 801 grade van vryheid), $\mathrm{P}<0.001)$.

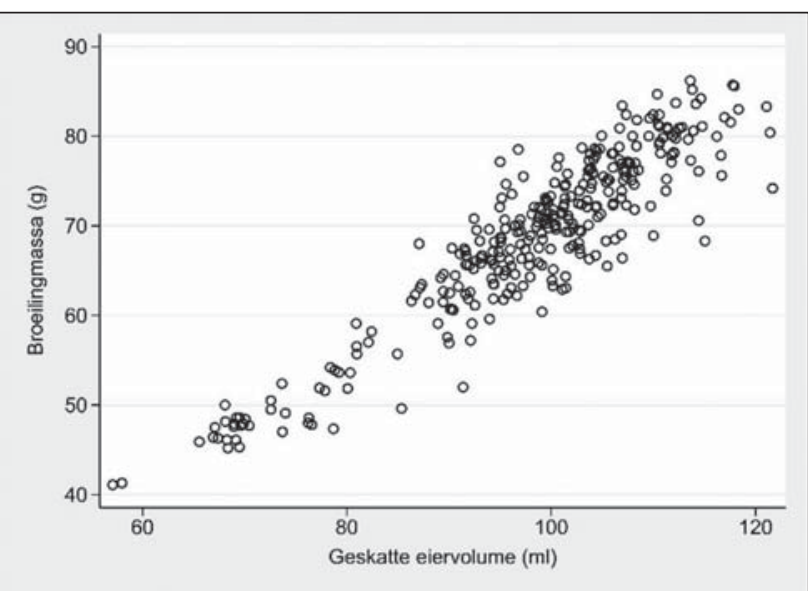

FIGUUR 2: Daar bestaan 'n sterk positiewe lineêre verband tussen die massa van broeilinge en die geskatte volume van die eiers waaruit hulle gebroei het ( $R 2=0.85, n=316$ ), alhoewel daar ook aansienlike variasie in broeilingmassa vir' $n$ bepaalde geskatte eiervolume voorkom

\section{Die variasie van die geskatte volume van uitgebroeide eiers en broeilingmassa binne en tussen broeisels}

Die intraklaskorrelasiekoëffisiënt vir die geskatte volume van uitgebroeide eiers, sonder inagneming van enige koveranderlike, was 0.849 , wat daarop dui dat $84.9 \%$ van die variasie in geskatte eiervolume die gevolg was van variasie tussen broeisels en $15.1 \%$ binne broeisels. Die effek van broeisel op geskatte eiervolume was hoogs betekenisvol ( $\chi^{2}=391.7$ (1 graad van vryheid), $\mathrm{P}<0.001,270$ geskatte eiervolumes in 34 broeisels wat elk minstens vyf geskatte eiervolumes gehad het). Figuur 4 a gee 'n visuele indruk van hierdie variasies: alhoewel geskatte eiervolume grootliks tussen broeisels gevarieer het, het beduidende variasie ook binne broeisels voorgekom.

Die intraklaskorrelasiekoëffisiënt vir broeilingmassa, sonder inagneming van enige koveranderlike, was 0.869 , wat daarop dui dat $86.9 \%$ van die variasie in broeilingmassa die gevolg was van variasie tussen broeisels en $13.1 \%$ binne broeisels. Die effek van broeisel op broeilingmassa was hoogs betekenisvol $\left(\chi^{2}=426.9\right.$ met een graad van vryheid, $\mathrm{P}<0.001,270$ broeilingmassas in 34 broeisels wat elk minstens vyf broeilingmassas gehad het). Figuur $4 \mathrm{~b}$ toon

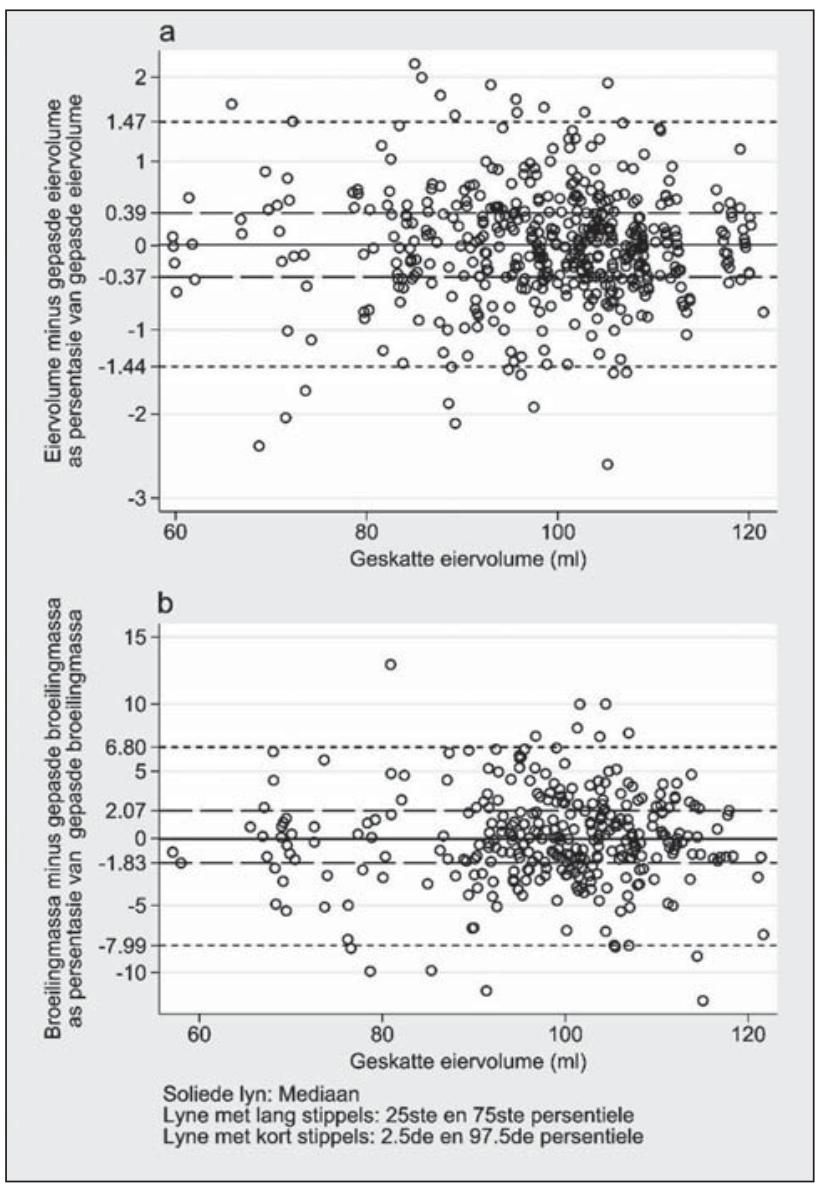

FIGUUR 3: Persentasie fout in die passing van 127 eiers se volumes op die skattings van hul volumes op grond van metings op 487 gemaskeerde fotobeelde van die eiers (grafiek a), en die persentasie fout in die passing van 316 broeilinge se massa op die skattings van die volumes van die eiers waaruit hul gebroei het op grond van metings op fotobeelde van die eierdoppe (grafiek b) 


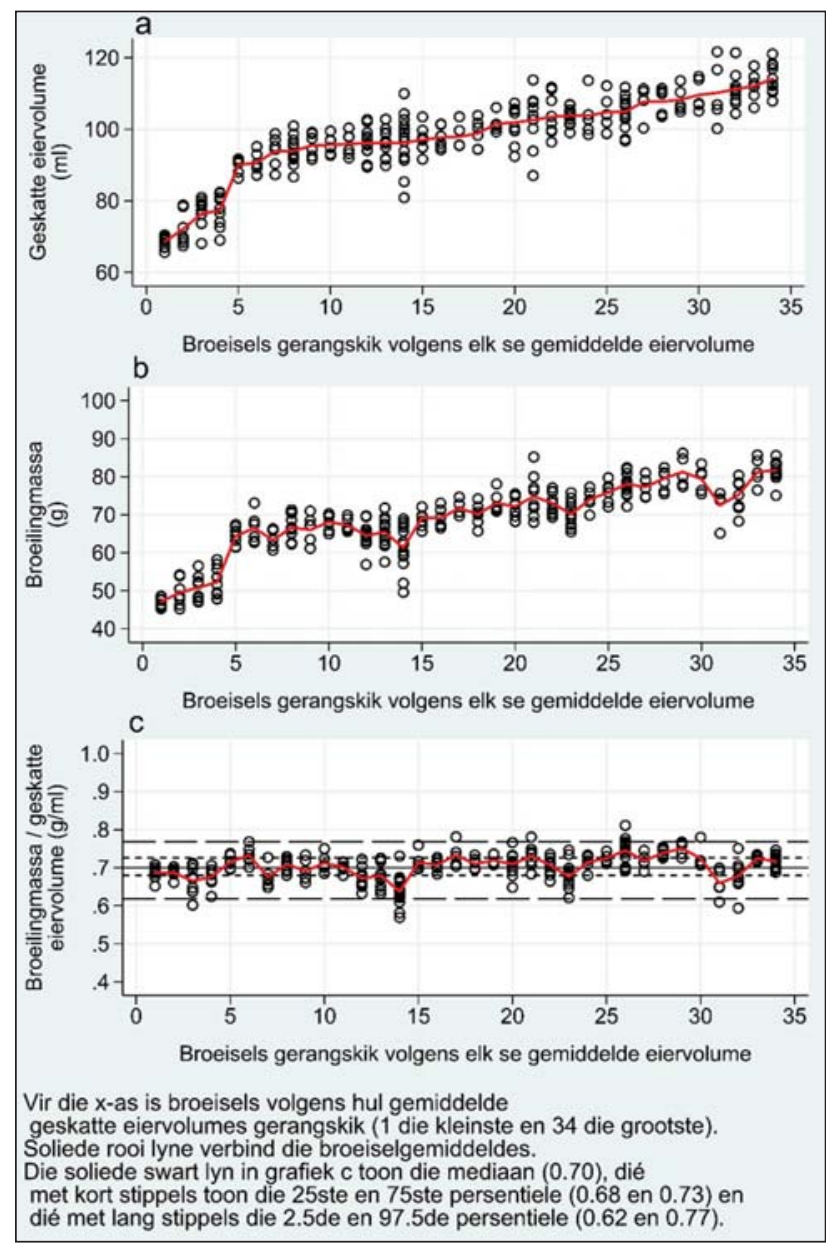

FIGUUR 4: Variasie in geskatte eiervolume (grafiek a), broeilingmassa (grafiek b) en broeilingmassa gedeel deur geskatte eiervolume (eierproduktiwiteit, grafiek c) tussen, sowel as binne 34 Nylkrokodilbroeisels wat elk minstens vyf geskatte eiervolumes met hul onderskeie broeilingmassas gehad het $(n=270)$

dat broeilingmassa, soos geskatte eiervolume in Figuur $4 a$, grootliks tussen broeisels gevarieer het en dat daar ook beduidende variasie binne broeisels voorgekom het. Figure $4 \mathrm{a}$ en $4 \mathrm{~b}$ toon ook dat broeilingmassa op soortgelyke wyse as geskatte eiervolume toegeneem het tussen broeisels wanneer die broeisels volgens hul gemiddelde geskatte eiervolumes georden is.

\section{Die produktiwiteit van eiers}

Anders as broeilingmassa wat toeneem na gelang die gemiddelde geskatte eiervolume van broeisels toeneem soos blyk uit Figuur 4b, toon Figuur 4c dat eierproduktiwiteit in ' $n$ band tussen ongeveer 0.6 en 0.8 varieer, ongeag broeisels se gemiddelde geskatte eiervolume.

Figuur 5 toon 'n histogram van die produktiwiteit van al 316 eiers in 51 broeisels. Die produktiwiteit van eiers het gevarieer van $0.57 \mathrm{~g} / \mathrm{ml}$ tot $0.81 \mathrm{~g} / \mathrm{ml}$ met 'n interkwartielvariasiewydte van $0.05 \mathrm{~g} / \mathrm{ml}$ en 'n variasiewydte van $0.15 \mathrm{~g} / \mathrm{ml}$ tussen die $2.5 \mathrm{de}$ en $97.5 \mathrm{de}$ persentiele. Hierdie resultate was dieselfde as wanneer slegs daardie 34 broeisels wat elk minstens vyf geskatte eiervolumes met hul onderskeie broeilingmassas gehad het in ag geneem is (Figuur 4c).

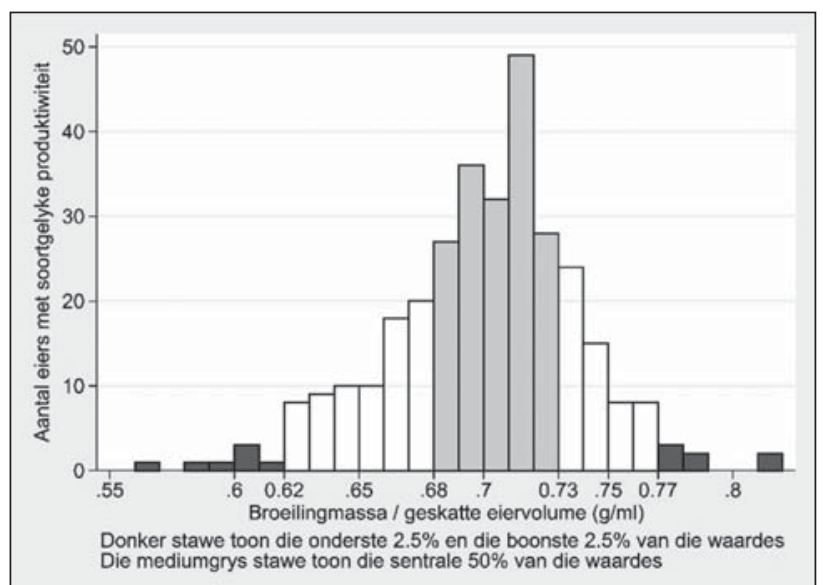

FIGUUR 5: Die produktiwiteit (broeilingmassa / geskatte eiervolume) van 316 Nylkrokodileiers van 51 broeisels

Die intraklaskorrelasiekoëffisiënt vir produktiwiteit, sonder inagneming van enige koveranderlike, was 0.454 , wat daarop dui dat $45.4 \%$ van die variasie in produktiwiteit tússen broeisels voorgekom het en 54.6\% daarbínne. Die effek van broeisel op produktiwiteit was hoogs betekenisvol $\left(\chi^{2}=111.3\right.$ met een graad van vryheid, $\mathrm{P}<0.001,270$ produktiwiteitswaardes in 34 broeisels wat elk minstens vyf produktiwiteitswaardes gehad het).

\section{Bespreking}

Afgesien van 'n positiewe lineêre verband tussen geskatte eiervolume en broeilingmassa, toon hierdie studie ook dat broeilingmassa vir ' $n$ bepaalde geskatte eiervolume varieer. Hierdie studie toon ook dat die verhouding tussen die massa van 'n broeiling en die geskatte volume van die eier waaruit dit gebroei het (die produktiwiteit van die eier) tussen eiers varieer.

Eiervolume sowel as broeilingmassa varieer grootliks tussen broeisels, met sowat $85 \%$ en $87 \%$ van die variasie in dié twee veranderlikes wat tussen broeisels voorkom en slegs sowat $15 \%$ en $13 \%$ tussen eiers van dieselfde broeisel. In teenstelling hiermee varieer eierproduktiwiteit hoofsaaklik bínne broeisels, met sowat $55 \%$ van die variasie wat tussen die eiers van dieselfde broeisel voorkom en sowat $45 \%$ tussen broeisels.

Die groeitempovan krokodille is van belang op kommersiële krokodilplase (Isberg et al., 2005). Navorsing op Crocodylus porosus broeilinge het teenstrydige bevindings opgelewer. Brien et al. (2014) kon geen beduidende effek van die massa van C. porosus broeilinge op hul groei toon nie, terwyl Brien et al. (2016) bevind het dat ligter C. porosus broeilinge vinniger gegroei het as swaarderes. Dit is onbekend of Nylkrodille se broeilingmassa verband hou met groeitempo na uitbroeiing. In die lig van die verskillende wyses waarop eiervolume, broeilingmassa en eierproduktiwiteit varieer is verdere navorsing aangedui om die verband tussen elkeen van hierdie veranderlikes en groeitempo na uitbroeiing in die Nylkrokodil te bepaal. 
Die oorsaak van die variasie in eierproduktiwiteit is onbekend. 'n Nylkrokodilwyfie lê haar eiers gedurende één nag in één gat en op plase word hulle die volgende oggend saam verwyder en saam, in dieselfde houer en teen dieselfde temperatuur en voggehalte, geïnkubeer vir 'n periode wat selde meer as $2-3 \%$ tussen eiers verskil. Die soortgelykheid in die hantering van die eiers van dieselfde broeisel maak dit onwaarskynlik dat die omgewing waaraan eiers blootgestel word nadat hulle gelê is die variasie in eierproduktiwiteit veroorsaak. Nelson et al. (2010) het aangetoon dat fetusse van die Amerikaanse alligator (Alligator mississippiensis) se massa met een gram toeneem vir elke gram waarmee dooiermassa afneem, wat daarop dui dat dooier 'n belangrike bepaler van die massa van fetusse en uiteindelik broeilinge is. Brown et al. (2019), het bevind dat die dooier van Nylkrokodileiers van $29 \%$ tot $62 \%$ (gemiddeld $43 \%$, s $=5.6 \%$ ) van hul massa beslaan. Variasie in dooiergrootte in eiers van dieselfde grootte kon dus die oorsaak wees van die variasie in eierproduktiwiteit wat in die huidige studie binne- sowel as tussen broeisels waargeneem is.

Die volume van die eiers waaruit die broeilinge in hierdie studie gebroei het is op grond van die uitgebroeide doppe geskat. Die metode waarmee die eiervolume op grond van uitgebroeide doppe geskat is, is dieselfde as die metode waarmee Nöthling et al. (2019) die volume van eiers met bekende volume op grond van gemaskeerde fotobeelde van die eiers geskat het. Die presisie waarmee die werklike volume van eiers op hul geskatte volume gepas kon word is betekenisvol beter as die presisie waarmee broeilingmassa op die geskatte volume van die eiers waaruit die broeilinge gebroei het, gepas kon word. Trouens, die interval tussen die $2.5 \mathrm{de}$ en $97.5 \mathrm{de}$ persentiel van die persentasiefout tussen die gepasde eiervolume en die werklike eiervolume was slegs een vyfde so wyd as die interval tussen die $2.5 \mathrm{de}$ en 97.5de persentiel van die persentasiefout tussen die gepasde broeilingmassa en die werklike broeilingmassa. Die variasie in eierproduktiwiteit is dus nie slegs vanweë foutiewe skatting van die uitgebroeide eiers se volume nie. Nogtans is verdere navorsing nodig waartydens die volume van eiers vóór inkubering, terwyl hulle heel is, presies bereken word met die metodes deur Nöthling et al. (2019) beskryf, waarna die broeiling wat elke eier uiteindelik oplewer geweeg word om hieruit die variasie in eierproduktiwiteit presies te bepaal. Navorsing is nodig om die mate waartoe eiermassa, wat makliker gemeet kan word as eiervolume, eiervolume kan vervang in die bepaling van eierproduktiwiteit.

Hierdie studie mag van waarde wees vir natuurbewaring: Doppe van eiers wat in nesse in die natuur uitgebroei het kan gebruik word om die volume van die eiers mee te skat, waaruit die waarskynlikste groottes van die broeilinge wat die eiers opgelewer het bepaal kan word. Ouer, groter krokodille lê groter eiers as jonger, kleineres (Huchzermeyer, 2003; Swanepoel et al., 2000). Wanneer die volume van eiers uit doppe van eiers wat in nesse in die natuur uitgebroei het geskat word, mag die geskatte eiervolume nuttig wees om die grootte van die wyfie wat die eiers gelê het te skat.

\section{Slotsom}

Daar bestaan 'n sterk, lineêre positiewe verband tussen die uitbroeimassa van Nylkrokodilbroeilinge en die geskatte volume van die eiers waaruit hulle gebroei het. Sonder inagneming van enige koveranderlike is $84.9 \%$ van die variasie in geskatte eiervolume en $86.9 \%$ van die variasie in broeilingmassa die gevolg van variasie tussen broeisels. Die verhouding tussen die massa van 'n broeiling en die geskatte volume van die eier waaruit dit gebroei het (die produktiwiteit van die eier) varieer tussen eiers, met $54.6 \%$ van die variasie as gevolg van variasie binne broeisels.

\section{Outeursbydrae}

JGM het JON tydens een van die twee jare gehelp om broeilinge en hul eiers tydens uitbroei te bekom, die eiers te fotografeer en die broeilinge te weeg, terwyl JON dit alleen gedoen het tydens die tweede jaar. JAN het die rekenaarprogram wat hy vroeër geskryf het (Nöthling et al., 2019) verfyn om die bruikbaarheid vir uitgebroeide doppe te verseker. JAN en JON het die foto's voorberei vir meting van die eierdopbeelde met die rekenaarprogram en om die volumes van die eiers te skat. JON het die data-analise gedoen. JON het die manuskrip in Afrikaans geskryf en daarna in Engels vertaal.

\section{Bedankings}

Die outeurs bedank die personeel van Le Croc Landgoed vir die geleentheid om materiaal en data te versamel. Ons dank ook aan die Navorsingstigting (National Research Foundation), omdat die aansporingsfonds vir gegradeerde navorsers (toekenningnommer 85836) wat hulle aan JON toegeken het, die studie deels befonds het. Dank ook aan verskeie assistente wat op verskillende tye gehelp het met data-insameling.

\section{Verwysings}

Behangana M, Lukwago W, Dendi D, Luiselli L, Ochanda D. 2017. Population surveys of Nile crocodiles (Crocodylus niloticus) in the Murchison Falls National Park, Victoria Nile, Uganda. European Journal of Ecology 3, 67-76. DOI 10.1515/eje2017-0015.

Botha H, Van Hoven W, Guillette Jr LJ. 2011. The decline of the Nile crocodile population in Loskop Dam, Olifants River, South Africa. Water SA 37 103-108.

Brien ML, Webb GJ, McGuinness K, Christian KA. 2014. The relationship between early growth and survival of hatchling saltwater crocodiles (Crocodylus porosus) in captivity. Plos One 9 (6):e100276.

Brien ML, Webb GJ, McGuinness KA, Christian KA. 2016. Effect of housing density on growth, agonistic behaviour, and activity in hatchling saltwater crocodiles (Crocodylus porosus). Applied Animal Behaviour Science 184, 141-149.

Brito JC, Martinez-Freiría F, Sierra P, Sillero N, Tarroso P. 2011. Crocodiles in the Sahara Desert: An update of distribution, habitats and population status for conservation planning in Mauritania. Plos One 6 (2):e14734.

Brown GJ, Forbes PBC, Myburgh JG, Nöthling JO. 2019. Nile crocodile (Crocodylus niloticus): Egg mass relative to egg component mass in unbanded and fertile eggs. Aquaculture 505, 423-430.

Calverley PM, Downs CT. 2014. Population status of Nile crocodiles in Ndumo Game Reserve, Kwazulu-Natal, South Africa (1971-2012). Herpetologica 70, 417-425. 
Combrink X, Warner JK, Downs CT. 2013. Crocodiles, in: Perissinotto R, Stretch DD Taylor RH (Eds.). Ecology and conservation of estuarine ecosystems: Lake S Lucia as a global model. Cambridge University Press, New York, pp. 333-353.

Deitz DC, Hines TC. 1980. Alligator nesting in North-Central Florida. Copeia No. 2, 249-258.

Feely JM. 2010. On the south-eastern range limits of the Nile crocodile: A review of its past and present occurrences in the Eastern Cape and Western Cape, South Africa. African Journal of Wildlife Research 40(2), 169-175.

Fergusson RA. 2010. Nile crocodile Crocodylus niloticus, in: Manolis SC, Stevenson C. (Eds.), Crocodiles: Status survey and conservation action plan, third ed. Crocodile Specialist Group, Darwin, pp. 84-89.

Ferreira SM, Pienaar D. 2011. Degradation of the crocodile population in the Olifants River Gorge of Kruger National Park, South Africa. Aquatic Conservation: Marine and Freshwater Ecosystems 21, 155-164.

Garnett ST, Murray RM. 1986. Parameters affecting the growth of the estuarine crocodile, Crocodylus porosus, in captivity. Australian Journal of Zoology 34 211-223.

Huchzermeyer FW. 2003. Crocodiles: Biology, husbandry and diseases. CABI Publishing, Cambridge, MA, USA.

Isberg SR, Thomson PC, Nicholas FW, Barker SG, Moran C. 2005. Quantitative analysis of production traits in saltwater crocodiles (Crocodylus porosus): II. Age at slaughter. Journal of Animal Breeding and Genetics 122, 370-377.

Khoza P. 2012. Comparative analysis of hatching rates and clutch sizes of Nile crocodile (Crocodylus niloticus) eggs collected on- and off -farm in Zimbabwe. Tropical Animal Health and Production 44, 905-909. DOI 10.1007/s11250-011 9985-z

Kofron C. 1990. The reproductive cycle of the Nile crocodile (Crocodylus niloticus). Journal of Zoology 221, 477-488.

Nelson TC, Groth KD, Sotherland PR. 2010. Maternal investment and nutrient use affect phenotype of American alligator and domestic chicken hatchlings. Comparative Biochemistry and Physiology, Part A 157, 19-27.
Nöthling JO, Nöthling JA, Myburgh JG. 2019. A model by which to estimate the volume of Nile crocodile eggs after they have hatched, Suid-Afrikaanse Tydskrif vir Natuurwetenskap en Tegnologie 38(1). English manuscript available at satnt.co.za/index.php/satnt/article/view/680/1533. Afrikaanse manuskrip beskikbaar by satnt.co.za/index.php/satnt/article/view/680.

Pooley AC. 1973. Conservation and management of crocodiles in Africa. Journal of the South African Wildlife Management Association 3, 101-103.

Rabe-Hesketh S, Skrondal A. 2012. Multilevel and longitudinal modelling using Stata. Volume 1: Continuous responses, third ed. Stata Press, College Station, Texas.

Steyn AGW, Smit CF, Strasheim C. 1998. Moderne statistiek vir die praktyk, Sesde Uitgawe. JL van Schaick Uitgewers, Pretoria.

Steyn F, Smit C, Vorster C. Editors. 2009, English-Afrikaans glossary of statistical terms. https://sastat.org.za/sites/default/fi les/documents/files/Eng_Afr_fin. pdf

Stoker C, Zayas MA, Ferreira MA, Durando M, Galoppo GH, Rodríguez HA, Repetti MR, Beldoménico HR, Caldini EG, Luque EH, Muñozde-Toro M. 2013. The eggshell features and clutch viability of the broad-snouted caiman (Caiman latirostris) are associated with the egg burden of organochlorine compounds. Ecotoxicology and Environmental Safety 98, 191-195.

Swanepoel DGJ, Ferguson NS, Perrin MR. 2000. Nesting ecology of Nile crocodiles (Crocodylus niloticus) in the Olifants River, Kruger National Park. Koedoe 43 $35-46$.

Tosun DD. 2013. Crocodile farming and its present state in global aquaculture Journal of FisheriesSciences.com 7, 43-57. DOI: 10.3153/jfscom.2013005.

Webb GJW, Buckworth R, Manolis SC. 1983a. Crocodylus johnstoni in the McKinlay River, N.T.VI.*. Nesting Biology. Australian Wildlife Research 10, 607-637.

Webb GJW, Sack GC, Buckworth R, Manolis SC. 1983b. An examination of Crocodylus porosus nests in two Northern Australian freshwater swamps, with an analysis of embryo mortality. Australian Wildlife Research 10, 571-605. 